\title{
Международное сотрудничество государств в области защиты прав лищ, перемещенных внутри страны
}

\author{
Иванов Д.В. *
}

В данной статье содержится описание истории развития международно-правового регулирования защиты лиц, перемещенных внутри страны (ЛПВС); основные теоретические аспекты рассматриваемой проблемы и международное сотрудничество государств по вопросу оказания помощи ЛПВС.

Ключевые слова: международное право; лица, перемещенные внутри страны (ЛПВС); вынужденный переселенец; вынужденная миграция.

Впервые вопрос о необходимости централизованного и организованного предоставления помощи ООН лицам, перемещенным внутри страны (ЛПВС), был рассмотрен на Международной конференции по вопросу о бедственном положении беженцев, репатриантов и перемещенных лиц в южной части Африки, состоявшейся в Осло 22-24 августа 1988 г. Предложение о проведении данной конференции было поддержано Генеральной Ассамблеей ООН. Целями конференции, среди прочего, являлось привлечение внимания международного сообщества к проблемам беженцев, репатриантов и ЛПВС в девяти государствах: Анголе, Ботсване, Лесото, Малави, Мозамбике, Свазиленде, Танзании, Замбии и Зимбабве. В ходе работы конференции предполагалось определить основные причины вынужденного перемещения населения в регионе, а также определить их экономические, социальные и гуманитарные потребности, проблемы и потребности принимающих их государств. Кроме того, по результатам конференции ее участники приняли Декларацию и План действий по гуманитарному вмешательству в данном регионе. На конференции обсуждались такие вопросы, как причины перемещения; оказание помощи вышеуказанным категориям лиц и их потребности; оказание помощи государствам убежища и/или государствам, принимающим ЛПВС; помощь в чрезвычайных обстоятельствах и помощь развивающимся странам.

\footnotetext{
* Иванов Дмитрий Владимирович - к.ю.н., профессор кафедры международного права МГИМО (У) МИД РФ. ilc48@mail.ru.
} 
24 августа 1988 г. были приняты Декларация и План действий по вопросу о бедственном положении беженцев, репатриантов и ЛПВС в южной части Африки. В Декларации были указаны основные причины вынужденного перемещения населения в рассматриваемом регионе, основополагающие принципы гуманитарной помощи, подчеркнута связь между оказанием поддержки, возмещением ущерба и помощью развивающимся странам, закреплен принцип «распределения бремени».

На тот момент особенно остро стоял вопрос о решении проблем ЛПВС ввиду отсутствия какой-либо международной организации, которая могла бы предоставлять ${ }^{1}$ им помощь. Поэтому в Плане действий на Генерального секретаря ООН была возложена обязанность по проведению исследований и консультаций с целью обеспечить своевременное осуществление и координирование программ помощи (пункт 21). В пункте 22 Плана действий был закреплен призыв к международному сообществу осуществлять сотрудничество в решении вопросов по безопасной доставке гуманитарной помощи. Согласно пункту 27 Плана действий принимающие страны и страны происхождения в сотрудничестве с Генеральным секретарем OAE (ныне - AC) и Верховным комиссаром ООН по делам беженцев должны способствовать возвращению ЛПВС, если на то позволяют обстоятельства ${ }^{2}$.

На Международной конференции по проблеме центральноамериканских беженцев в Гватемале в 1989 г. также было обращено внимание на положение лиц, перемещенных внутри страны. Решение о проведении данной конференции было принято в связи с необходимостью решения проблем беженцев и ЛПВС в Центральной Америке. Еще в 1987 г. в Гватемале на совещании на высшем уровне Эскипулас II было подписано соглашение «Пути установления прочного и стабильного мира в Центральной Америке». В разделе 8 соглашения государства закрепили обязательство предоставлять защиту и помощь беженцам и ЛПВС, ставшими таковыми в результате регионального кризиса, в особенности, в том, что касается здравоохранения, образования, трудоустройства, и безопасности и, кроме того, способствовать

\footnotetext{
${ }^{1}$ Более подробно об этом см. Иванов Д.В. Беженцы в современном международном праве. - М.: Междунар. Отношения, 2006.; Иванов Д.В. Бобринский Н.А. Правовой статус лиц, ищущих убежище, в современном международном праве. - М.: Статут, 2009. ${ }^{2}$ International Conference on the Plight of Refugees, Returnees and Displaced Persons in Southern Africa (SARRED): Report of the Secretary-General: 19 October 1988, A/43/717. URL: http://www.unhcr.org/refworld/docid/3ae68f410.html (accessed 30.12.2010).
} 
их репатриации, переселению или перемещению, при условии, что данные действия являются добровольными и осуществляются с учетом индивидуальных обстоятельств ${ }^{3}$. Исполнительная комиссия, созданная в соответствии с соглашением, приняла решение учредить Подкомиссию по вопросам беженцев и ЛПВС в составе представителей стран Центральной Америки для изучения и выработки рекомендаций с целью содействия и облегчения добровольной репатриации, а также механизмы регионального сотрудничества 4 . Таким образом, Конференция по проблеме центральноамериканских беженцев стала еще одним этапом в процессе принятия и разработки новых механизмов международного сотрудничества в сфере вынужденной миграции в регионе.

На конференции были приняты Декларация и Согласованный план действий в интересах центральноамериканских беженцев, репатриантов и ЛПВС 5 . План действий предусматривал реализацию различных программ, направленных на улучшение положения ЛПВС. Такие программы предусматривали упрощение процедуры возвращения вынужденных мигрантов в страну происхождения, восстановление их сообществ или их размещение в пределах национальной территории или в местах их фактического проживания. При этом основной целью таких действий должна была стать интеграция ЛПВС и их участие в процессе развития на тех же условиях, на которых в нем участвуют граждане соответствующего принимающего государства (пункт30).

Экономический и Социальный Совет ООН 27 июля 1990 г. принял резолюцию 1990/78, в которой обратился к Генеральному секретарю ООН с просьбой «организовать в рамках всей системы ООН проведение обзора для оценки опыта и возможностей различных организаций в деле координации помощи всем беженцам, ЛПВС и репатриантам и оценки всего спектра их потребностей» и на основании такого

${ }^{3}$ Guatemalan agreement for peace in Central America: of Aug. 7, 1987. URL: http:// findarticles.com/p/articles/mi_m1079/is_n2127_v87/ai_6101621/pg_3/?tag=content;col1 (accessed: 30.12.2010).

${ }^{4}$ Помощь центральноамериканским беженцам, репатриантам и лицам, перемещенным внутри страны: Резолюция Генеральной Ассамблеи ООН: 42/110, A/RES/42/110, 93-е пленарное заседание, 07.12.1987 года. URL: http:/daccess-ods.un.org/access.nsf/ Get?Open\&DS=A/RES/42/110\&Lang=R (дата обращения: 30.12.2010).

${ }^{5}$ Declaration and Concerted Plan of Action in Favour of Central American Refugees, Returnees and Displaced Persons (CIREFCA): of 31 May 1989. URL: http://www.unhcr. org/refworld/docid/3fbb5d094.html (accessed: 30.12.2010). 
обзора «рекомендовать пути максимального расширения сотрудничества и координации между различными организациями системы Организации Объединенных Наций» для обеспечения реагирования на проблемы беженцев, ЛПВС и репатриантов ${ }^{6}$.

В 1990 г. УВКБ ООН и Международный совет добровольных учреждений (МСДУ), Конфедерация добровольных организаций, занимающаяся международной деятельностью в области развития, а также в социальной и гуманитарной сферах, провели ряд консультаций по основным вопросам сотрудничества с участием небольшого числа неправительственных организаций и 20 Региональных Представительств УВКБ ООН на местах. Возросли роль и значение неправительственных организаций, выступающих в качестве партнеров $\mathrm{OOH}$ по оперативной деятельности и предоставлению международной защиты беженцам и ЛПВС. Данное обстоятельство нашло отражение в справочном документе по вопросу о взаимоотношениях между УВКБ ООН и неправительственными организациями. В июне 1993 г. УВКБ ООН и МСДУ провели консультации относительно проекта «Партнерство в действии» (ПАРИНАК). Рассматривавшиеся вопросы отбирались по принципу их соответствия актуальным проблемам и включали в себя вопросы о международной защите, лицах, перемещенных внутри страны, готовности к чрезвычайным ситуациям и мерах по их ликвидации, переходе от оказания помощи к процессу восстановления и далее к обеспечению развития, а также вопрос о партнерстве. В Каракасе, Катманду, Тунисе, Бангкоке, Аддис-Абебе и Будапеште были проведены региональные совещания. На каждом совещании присутствовали представители в среднем 85 неправительственных организаций, и выдвигался, с учетом реального положения и потребностей региона, комплекс региональных рекомендаций. Приблизительно 500 неправительственных организаций, в основном национальных, внесли свой вклад в разработку рекомендаций, которые вошли в Декларацию и План действий, принятые в Осло на Глобальной конференции неправительственных организаций и УВКБ ООН по вопросам ПАРИНАК (Осло, 6-9 июня 1994 г.). В Плане действий, содержащем

\footnotetext{
${ }^{6}$ Всеобъемлющее исследование по вопросам прав человека, относящимся к лицам, перемешенным внутри страны. Подготовлено представителем Генерального секретаря г-ном Франсисом М. Денгом во исполнение резолюции 1992/73 Комиссии по правам человека: 21.01.1993. E/CN.4/1993/35. C.5. URL: http://daccess-ods.un.org/TMP/4900326. html (дата обращения: 30.12.2010).
} 
134 рекомендации, была предпринята попытка разработать программы гуманитарной деятельности УВКБ ООН и неправительственных организаций на будущее 7

В Декларации говорится о необходимости разработки комплексного подхода к защите и помощи ЛПВС, который основывался бы на четко определенных юридических и практических критериях.

В Плане действий содержится целый раздел, посвященный ЛПВС, который включает ряд рекомендаций по защите и оказанию помощи данной категории вынужденных мигрантов (Рекомендации 40-59). В данном документе подчеркивается необходимость разработки и правового закрепления общего определения понятия «ЛПВС», содержатся рекомендации по совершенствованию деятельности международных органов и организаций, в компетенцию которых входит защита вынужденных мигрантов; подчеркивается необходимость разработки механизмов, которые упростят выдачу документов ЛПВС и др. ${ }^{8}$

В июне 1994 г. УВКБ ООН и неправительственные организации приступили к осуществлению рекомендаций Плана действий, принятого в Осло, с учетом региональных особенностей. Рекомендации, в которых речь идет о ЛПВС, имели основополагающее значение для деятельности УВКБ ООН и неправительственных организаций в Шри-Ланке, где в результате конфликта ЛПВС стали несколько сот тысяч человек. В некоторых случаях возникали смешанные потоки вынужденных мигрантов, состоявших из беженцев и ЛПВС. Например, в Шри-Ланке те, кто возвращался из эмиграции в Индии, могли оказаться среди лиц, перемещенных внутри Шри-Ланки. Аналогичное положение наблюдалось в Бурунди и Руанде. В связи с этим рекомендации ПАРИНАК нашли, с учетом сложности проблемы, широкое применение 9 .

7 Мероприятия по выполнению рекомендаций Международной конференции по народонаселению и развитию: международная миграция. Деятельность межправительственных и неправительственных организаций в области международной миграции: Доклад Генерального секретаря: E/CN.9/1997/5 10.01.1997. C. 20-21. URL: www.un.org/ documents/ecosoc/cn9/1997/russian/ecn91997-1r.pdf (дата обращения: 30.12.2010).

${ }^{8}$ См. текст Декларации и Плана действий: Oslo Declaration and Plan of Action, 9 June 1994, available at: http://www.unhcr.org/refworld/docid/3ae68f3d8.html (accessed: 30.12.2010).

${ }^{9}$ Мероприятия по выполнению рекомендаций Международной конференции по народонаселению и развитию: международная миграция. Деятельность межправительственных и неправительственных организаций в области международной миграции: Доклад Генерального секретаря: E/CN.9/1997/5 10.01.1997. C. 21. URL: www.un.org/ documents/ecosoc/cn9/1997/russian/ecn91997-1r.pdf (дата обращения: 30.12.2010). 
В сентябре того же года в Каире прошла Международная конференция по народонаселению и развитию. В ходе конференции также обсуждались различные проблемы ЛПВС, а результатом данного обсуждения стали определенные рекомендации. В отчете о конференции 10 подчеркивается, что целями сотрудничества в области защиты ЛПВС являются обеспечение безопасности данной категории лиц, особенно детей и женщин, пожилых, борьба с причинами их перемещения, упрощение возвращения таких лиц в места их обычного проживания; искоренение всех форм вынужденной миграции, включая «этнические чистки». Согласно разработанным на конференции рекомендациям государства должны бороться с причинами вынужденного перемещения населения внутри страны, оказывать помощь ЛПВС, включая выплату компенсаций, особенно тем из них, которые не могут возвратиться в места своего обычного проживания в ближайшее время. Кроме того, ЛПВС должны иметь доступ к начальному образованию, возможность трудоустройства, право на пользование услугами в области здравоохранения. Все меры должны приниматься на национальном уровне параллельно с усилиями, предпринимаемыми международным сообществом.

Работа по изучению ситуации, в которой находятся ЛПВС, в различных регионах мира велась непосредственно ООН. С этой целью в 1992 г. впервые была учреждена должность Представителя Генерального секретаря ООН по правам ЛПВС, которому была поручена разработка международных стандартов, касающихся вынужденного перемещения внутри страны.

В 1993 г. по требованию Комиссии ООН по правам человека Представитель Генерального секретаря по правам ЛПВС Френсис М. Денг провел анализ действующих международно-правовых актов, которые могут регулировать правовое положение ЛПВС. В результате проведенного исследования он пришел к выводу, что действовавшие на тот момент международно-правовые акты предоставляли достаточно широкую защиту ЛПВС. Однако в своем исследовании он подчеркнул необходимость разработки и принятия международно-правовых актов, отражающих специфику правового положения ЛПВС 11. В част-

${ }^{10}$ Report of the International conference on population and development Cairo. 5-13 September 1994. A/CONF.171/13. 18 October 1994. URL: http://www.un.org/popin/ icpd/conference/offeng/poa.html (accessed: 30.12.2010).

${ }^{11}$ См. Выводы Представителя Генерального секретаря по правам ЛПВС: Further promotion and encouragement of human rights and fundamental freedoms, including the question of the programme and methods of work of the Commission: human rights, mass 
ности, он пришел к выводу о том, что прямой запрет на принудительное перемещение содержится только в международном гуманитарном праве и в международно-правовых актах, регулирующих правовое положение коренных народов. Напротив, в общем международном праве о правах человека такой запрет предусматривается лишь косвенно, в частности, в отношении свободы передвижения, запрета посягательства на неприкосновенность жилища. Однако эти международно-правовые нормы, по мнению Представителя, не могут распространяться на все случаи принудительного перемещения. Отсутствие четкой правовой регламентации о вынужденной миграции таких лиц, как ЛПВС в международном праве защиты и поощрения прав человека привело к неопределенности их статуса в международном праве ${ }^{12}$. На основе данного исследования были разработаны Руководящие принципы по вопросу о перемещении лиц внутри страны 1998 г. (далее - Руководящие принципы).

Со временем Руководящие принципы получили широкое признание. В том, что касается ответственности государств, данные стандарты основываются на двух основных положениях. Во-первых, суверенитет государства подразумевает не только право государств на самостоятельные действия, но также обязанность предоставлять защиту и помощь без дискриминации своему населению, включая ЛПВС, в соответствии с международным правом в области защиты и поощрения прав человека и международным гуманитарным правом. Во-вторых, лица, перемещенные внутри своей собственной страны, имеют те же права, что и все население в целом, но в результате перемещения данные лица становятся наиболее уязвимыми, поэтому государства должны принять особые меры по защите и помощи ЛПВС. Руководящие принципы

exoduses and displaced persons. Internally displaced persons. Report of the Representative of the Secretary-General, Mr. Francis M. Deng, submitted pursuant to Commission on Human Rights resolution 1995/57. Compilation and analysis of legal norms. E/CN.4/1996/52/Add.2. 5 December 1995. URL: http://www.unhchr.ch/Huridocda/Huridoca.nsf/TestFrame/75550e e91a4fb1ff802566cc005c2c63? Opendocument (accessed: 30.12.2010).

12 Further promotion and encouragement of human rights and fundamental freedoms including the question of the programme and methods of work of the Commission questions of human rights, mass exoduses and displaced persons: Report of the Representative of the Secretary-General, Mr. Francis Deng, submitted pursuant to Commission on Human Rights resolution 1997/39. Addendum. Compilation and Analysis of Legal Norms, Part II: Legal Aspects Relating to the Protection against Arbitrary Displacement. E/CN.4/1998/53/Add.1. 11 February 1998. URL: http:/www.unhchr.ch/Huridocda/ Huridoca.nsf/TestFrame/49dc6 63a776b2cc2c125661e002d5588? Opendocument (accessed: 30.12.2010). 
распространяются на все этапы перемещения и основаны на действующих нормах международного права в области защиты прав человека и стандартах международного гуманитарного права ${ }^{13}$.

Некоторые вопросы вызывает сам термин «лица, перемещенные внутри страны», особенно его перевод с английского языка. В документах $\mathrm{OOH}$ на английском языке для обозначения данной категории лиц используется термин “internally displaced persons”, который переводится как «внутренне перемещенные лица», но, чаще всего, «лица, перемещенные внутри страны».

В аналитическом докладе Генерального секретаря ООН по вопросу о лицах, перемещенных внутри страны, который был представлен Комиссии ООН по правам человека на ее сорок восьмой сессии в 1992 г,, используется термин «лица, перемещенные внутри страны» для определения лиц, «которые были вынуждены в большом числе покинуть свои жилища внезапно или неожиданно в результате вооруженного конфликта, внутренних раздоров, систематических нарушений прав человека или стихийных бедствий, или вызванных деятельностью человека катастроф и которые по-прежнему находятся на территории своей собственной страны» (пункт 17). УВКБ ООН выразило мнение, что данное определение является «удачным отправным пунктом для рассмотрения проблемы лиц, перемещенных внутри страны». Однако УВКБ ООН указало на то, что применение в качестве одного из критериев «большого числа» «может привести к субъективной оценке, которая в свою очередь привнесет элемент неточности». Некоторые международные организации заявили, что определение, содержащееся в аналитическом докладе, является неоправданно узким и не охватывает ряд лиц или группы лиц, нуждающихся в международной защите. Международная организация по миграции (MOM) также выступила против исключения из рабочего определения небольших групп лиц, поскольку, в частности, права, которые затрагиваются, являются в основе своей правами личности ${ }^{14}$.

${ }^{13}$ Brookings-Bern Project on Internal Displacement, Protecting Internally Displaced Persons: A Manual for Law and Policymakers, October 2008. P. 3-4. URL: http://www.unhcr.org/ refworld/docid/4900944a2.html (accessed: 11.01.2011).

14 Всеобъемлющее исследование по вопросам прав человека, относящимся к лицам, перемешенным внутри страны. Подготовлено представителем Генерального секретаря г-ном Франсисом М. Денгом во исполнение резолюции 1992/73 Комиссии по правам человека: 21.01.1993. E/CN.4/1993/35. C. 34-35. URL: http://daccess-ods.un.org/ TMP/4900326.html (дата обращения: 30.12.2010). 
В самих Руководящих принципах было закреплено следующее определение: «перемещенными внутри страны лицами считаются лица, или группы лиц, которых заставили или вынудили бросить или покинуть свои дома или места обычного проживания, в частности в результате или во избежание последствий вооруженного конфликта, повсеместных проявлений насилия, нарушений прав человека, стихийных или вызванных деятельностью человека бедствий, и которые не пересекали международно признанных государственных границ» (пункт 2).

Категорию ЛПВС необходимо отличать от других схожих категорий вынужденных мигрантов. ЛПВС находятся в сходном положении с беженцами, однако, их отличие от последних очевидно - ЛПВС являются лицами, которые были вынуждены сменить место проживания в пределах одного государства по причинам, перечень которых не является ограниченным.

Следует отметить, что в некоторых документах встречается понятие «лица, перемещенные за пределы страны» ("externally displaced persons"). Так, согласно пункту 7 уже цитировавшегося Плана действий, принятого на Международной конференции по проблеме центральноамериканских беженцев, под данным термином подразумеваются «лица, которые в результате кризиса не могут обеспечивать себя и вести обычный образ жизни вне зависимости от того, существует ли угроза их существованию, безопасности или свободе в результате конфликта и которые в связи с этим были вынуждены переехать в соседние страны». Таким образом, главной отличительной чертой этой категории лиц является перемещение за пределы родной страны, что является одной из характеристик, присущих категории беженцев. Однако лица, перемещенные за пределы страны, необязательно являются объектом преследования, гонений, насилия, наличия непосредственной опасности. По смыслу рассматриваемого документа данная категория населения четко отделена, несмотря на сходство, от беженцев.

В документах вышерассмотренных конференций часто встречается понятие «перемещенные лица» (“displaced persons"). Этот термин несколько устарел и в современное время используется редко. Традиционно под ним понимаются лица, насильно вывезенные немецкими войсками с оккупированных территорий для работы в Германию в период Второй мировой войны. Однако анализ вышеуказанных документов показывает, что данный термин включает в себя лиц, которые находятся в схожих с беженцами условиях, но не могут быть к ним отнесены. 
В законодательстве РФ и международно-правовых актах, принятых в рамках СНГ, был закреплен термин «вынужденный переселенец». Согласно статье 1 Закона РФ «О вынужденных переселенцах» от 19 февраля 1993г. № 4530-115 вынужденный переселенец - это гражданин РФ, покинувший место жительства вследствие совершенного в отношении него или членов его семьи насилия или преследования в иных формах либо вследствие реальной опасности подвергнуться преследованию по признаку расовой или национальной принадлежности, вероисповедания, языка, а также по признаку принадлежности к определенной социальной группе или политических убеждений, ставших поводами для проведения враждебных кампаний в отношении конкретного лица или группы лиц, массовых нарушений общественного порядка. Вынужденным переселенцем может быть признан гражданин РФ, вынужденный покинуть место жительства на территории иностранного государства и прибывший на территорию РФ; гражданин РФ, вынужденный покинуть место жительства на территории одного субъекта и прибывший на территорию другого субъекта РФ. В данную категорию могут также быть включены и лица, не являющиеся гражданами РФ: иностранный гражданин или лицо без гражданства, постоянно проживающие на законных основаниях на территории РФ и изменившие место жительства в пределах ее территории по вышеуказанным обстоятельствам. Таким образом, данное определение отражает особенности административно-территориального деления страны: перемещение должно осуществляться из одного субъекта федерации в другой. Кроме того, оно включает две категории лиц - возвратившихся в связи с предусмотренными обстоятельствами в Россию из иностранного государства и лиц, перемещенных в пределах территории РФ. Представляется, что последняя категория в определенной части соответствует ЛПВС. Однако следует отметить, что определение, закрепленное в Законе РФ «О вынужденных переселенцах», является достаточно узким, поскольку не содержит широкого перечня причин перемещения. В Руководящих принципах предусмотрен открытый перечень таких причин и закреплены такие причины, как стихийные бедствия, бедствия, вызванные человеком и др.

15 О вынужденных переселенцах: Закон от 19.02.1993 № 4530-1 // Собрание законодательства РФ. 1995. № 52. - С. 5110. 
В статье 2 Соглашения о помощи беженцам и вынужденным переселенцам от 24 сентября 1993 г. ${ }^{16}$, предусматривается, что вынужденным переселенцем признается лицо, которое, являясь гражданином Стороны, предоставившей убежище, было вынуждено покинуть место своего постоянного жительства на территории другой Стороны вследствие совершенного в отношении его или членов его семьи насилия или преследования в иных формах, либо реальной опасности подвергнуться преследованию по признаку расовой или национальной принадлежности, вероисповедания, языка, политических убеждений, а также принадлежности к определенной социальной группе в связи с вооруженными и межнациональными конфликтами. Данной статье Соглашения было дано толкование Экономическим судом СНГ, который в одном из своих решений постановил, что в определении содержится четыре критерия, которым должно удовлетворять лицо, чтобы быть признанным в качестве вынужденного переселенца в соответствии с Соглашением в государстве, которое является его участником: лицо должно быть гражданином государства, предоставившего убежище (государства въезда); лицо должно быть вынуждено покинуть место своего постоянного жительства, причем последнее должно находиться на территории другого государства (государства выезда), при этом как государство въезда, так и государство выезда должны быть участниками Соглашения; причиной, по которой лицо вынуждено покинуть государство, должно быть совершенное насилие или преследование в иных формах, либо реальная опасность подвергнуться преследованию. Причем насилие или преследование в иных формах может быть совершено не только в отношении самого лица, но и против членов его семьи. Определение содержит исчерпывающий перечень признаков, по которым должно совершаться насилие или преследование или должна существовать реальная опасность подвергнуться преследованию: расовая или национальная принадлежность, вероисповедание, язык, политические убеждения, а также принадлежность к определенной социальной группе; должна существовать связь между совершением насилия или преследования или существованием реальной опасности подвергнуться преследованию и вооруженными и межнациональными конфликтами. Для признания лица в качестве вынужденного переселенца

${ }^{16}$ Соглашение о помощи беженцам и вынужденным переселенцам: от 24.09.1993 // Российская газета. № 22. 28.01.1995. 
в соответствии с Соглашением необходимо и достаточно установить, что оно удовлетворяет всем критериям, содержащимся в определении ${ }^{17}$.

Таким образом, согласно Соглашению вынужденный переселенец это лицо, которое имеет гражданство государства въезда, но проживает на территории другого государства - государства выезда. Данное лицо возвращается в свою страну в связи с предусмотренными в Coглашении причинами. Очевидно, что данное определение отличается от определения, закрепленного в российском законодательстве, которое включает две категории лиц.

В настоящее время на региональном уровне осуществляется разработка различных стандартов и международно-правовых актов, регулирующих правовой статус и защиту ЛПВС. Так, 11 ноября 2010 г., была принята Бразильская декларация о защите беженцев и лиц без гражданства ${ }^{18}$, в которой подчеркнута необходимость дальнейшего поиска долгосрочных решений проблем ЛПВС и содержится призыв обмениваться опытом в области оказания помощи ЛПВС и их защиты, полученного при осуществлении Мексиканской декларации и Плана действий, которые признаются важным инструментом сотрудничества государств по оказанию помощи ЛПВС и беженцам. В Декларации было также отмечено, что действующее национальное законодательство государств о беженцах и ЛПВС в государствах континента учитывает особенности, связанные с полом, возрастом, различия в положении данных лиц для того, чтобы оказывать помощь с учетом особых обстоятельств женщинам, мужчинам, детям, пожилым, инвалидам, коренным народам и выходцам из Африки.

Но наибольших успехов в международно-правовом регулировании защиты ЛПВС удалось достичь на африканском континенте. По данным Африканского союза ${ }^{19}$, в январе 2009 г. в Африке насчитывалось приблизительно 11,6 миллионов ЛПВС. Основными причинами вынужденного внутреннего перемещения населения в Африке являются вооруженные конфликты, а также природные бедствия и реализация строительных проектов. Именно поэтому государствами данного кон-

${ }_{17}^{17}$ Решение Экономического суда СНГ от 11.09.2006 № C-1/14-96. URL: http://www. sudsng.org/database/deed/9_1996.html (дата обращения: 11.01.2011).

${ }^{18}$ On the Protection of Refugees and Stateless Persons in the Americas Brasilia: Declaration of 11.11. 2010. URL: http://www.unhcr.org/4cdd3fac6.html (accessed: 11.01.2011).

${ }^{19}$ First ever au summit on forced displacement starts Kampala, Uganda 22 October 2009: Press release. URL: http://www.africa-union.org/root/au/index/index_october_2009.htm (accessed: 11.01.2011). 
тинента предпринимаются наиболее активные меры по поиску решений проблем данной категории вынужденных мигрантов.

В рамках Международной конференции по району Великих озер в Африке 15 декабря 2006 г. был принят Пакт о безопасности, стабильности и развитии в районе Великих озер ${ }^{20}$. Статья 12 Пакта предусматривает принятие Протокола по вопросу защиты ЛПВС и оказания им помощи, согласно которому государства, среди прочего, принимают обязательство по имплементации Руководящих принципов по вопросу о перемещении лиц внутри страны 1998 г. в национальное законодательство. В 2006 г. Протокол 21 был принят, а в 2008 г. вступил в силу. На настоящий момент данный документ является единственным действующим международным договором о ЛПВС. Однако Пакт и Протокол были ратифицированы ограниченным числом стран - 11 государствами - участниками конференции и действует, таким образом, на субрегиональном уровне. В Протоколе предусмотрена достаточно узкая цель - имплементация Руководящих принципов в законодательство государств - участников Протокола. По этим причинам данный договор не может стать основополагающим международным соглашением для защиты ЛПВС в Африке.

Наоборот, Конвенция Африканского союза о защите лиц, перемещенных внутри страны, и оказании им помощи в Африке от 23 октября 2009 года ${ }^{22}$, если ее ратифицируют все страны - члены Африканского союза, будет распространяться на 53 государства. Таким образом, Конвенция представляет собой международный договор, который будет действовать на региональном уровне. Конвенция состоит из 23 статей. Основные положения Конвенции предусматривают обязательство государств по соблюдению прав ЛПВС без какой-либо дискриминации; определения, включающие определение ЛПВС, соответствующее положениям Руководящих принципов (статья 1); цели (статья 2);

${ }^{20}$ On Security, Stability and Development for the Great Lakes: Pact of 15.12.2006. URL: http://www.internal-displacement.org/8025708F004BE3B1/(httpInfoFiles)/60ECE277A8ED A2DDC12572FB002BBDA7/\$file/Great\%20Lakes\%20pact_en.pdf(accessed: 11.01.2011). ${ }^{21}$ On the Protection and Assistance to Internally Displaced Persons: Protocol of 30.11.2006. URL: http://www.internal-displacement.org/8025708F004BE3B1/(httpInfoFiles)/29D287 2A54561F66C12572FB002 BC89A/\$file/Final\%20protocol\%20Protection\%20IDPs\%20 -\%20En.pdf (accessed: 11.01.2011).

${ }^{22}$ For the Protection and Assistance of Internally Displaced Persons: Convention of 23.10.2009. URL: http://www.internal-displacement.org/8025708F004BE3B1/(httpIn foFiles)/0541BB5F1E5A133BC12576 B900547976/\$file/Convention(En).pdf (accessed: 11.01.2011). 
обязательства государств (статьи 3-5, 9-13); обязательства международных организаций и гуманитарных учреждений (статья 6); обязательства вооруженных групп (статья 7); обязательства Африканского союза (статья 8); контрольный механизм (статья 14); заключительные положения (статьи 15-23).

В Конвенции закреплены более широкие цели, чем в предыдущем документе. Цели Конвенции состоят в том, чтобы развить и укрепить региональные и национальные меры для устранения основных причин внутреннего перемещения; создать правовые рамки для предотвращения внутреннего перемещения и для защиты ЛПВС, а также для поиска долгосрочных решений данной проблемы; закрепить обязательства государств, а также вооруженных групп и негосударственных субъектов в отношении внутреннего перемещения и защиты ЛПВС.

Одной из положительных черт Конвенции является достаточно широкий перечень причин внутреннего перемещения, который включает природные бедствия, антропогенные катастрофы, изменение климата, осуществление строительных проектов (проектов в области развития). Следует обратить внимание на тот факт, что в Конвенции не используется понятие «широкомасштабные проекты в области развития», в отличие от Руководящих принципов и Протокола по вопросу защиты ЛПВС и оказания им помощи. Вместо него используется термин «проект». Такая формулировка представляется наиболее удачной, поскольку является более широкой, что упрощает применение Конвенции на практике и ее толкование.

Несомненным достоинством Конвенции является детальное изложение обязательств государств, которые делятся на обязательства общего характера; обязательства, касающиеся защиты от внутреннего перемещения; обязательства, касающиеся защиты и помощи; обязательства, касающиеся защиты в ходе внутреннего перемещения; обязательства в случае внутреннего перемещения в связи с осуществлением проектов; обязательства, касающиеся возвращения, интеграции или переселения ЛПВС; обязательства по выплате компенсации; обязательства по регистрации ЛПВС.

Одним из важнейших положений Конвенции является пункт 5 статьи 4 и пункт 5 статьи 11, закрепляющие обязательства государств по отношению к сообществам, которые находятся в особой зависимости от своих земель и привязаны к ним. Государства должны защищать их от перемещения, в случае если не затрагиваются первостепенные 
государственные интересы. Данная формулировка является более мягкой по сравнению, в частности, с Принципом 9 Руководящих принципов и пунктом 1 с) статьи 4 Протокола по вопросу защиты лиц, перемещенных внутри страны 2006 г. о специальной защите таких сообществ. В случае возвращения сообществ занимаемые ими ранее земли должны быть беспрепятственно им возвращены.

Структура Конвенции такова, что основной упор делается не на детальное описании правового статуса ЛПВС, а на четкое формулирование обязательств государств. Это следует отнести к одному из недостатков данного международного соглашения. Однако большинство юристов $^{23}$ выделяют другие недостатки Конвенции. Во-первых, речь идет о том, что закрепленное в Конвенции положение о недискриминации является слишком узким и не содержит достаточное количество оснований, по которым запрещается дискриминация. Вместе с тем, в преамбуле Конвенции государства подтверждают свою приверженность принципу защиты прав ЛПВС без дискриминации любого рода. Следует, однако, согласиться с критическими замечаниями, связанными с отсутствием в данном международном договоре положения о том, что ЛПВС пользуются теми же правами, что и другие лица в соответствующем государстве (Принцип 1, пункт 1 Руководящих принципов).

Во-вторых, Конвенция закрепляет обязательства негосударственных субъектов, которые не могут стать ее участниками, в частности, в статье 7. Со своей стороны отметим, что если толковать данную статью с учетом пункта 11 статьи 5 Конвенции ${ }^{24}$, то можно утверждать, что речь идет скорее об обязательстве государств не допускать указанных в Конвенции нарушений, совершаемых вооруженными группами.

В-третьих, Конвенция не предусматривает учреждения эффективных механизмов контроля в отношении ее применения. Согласно распространенному мнению, Конференция государств - участников Конвенции не может рассматриваться как эффективный контрольный механизмом.

Несмотря на вышеуказанные недостатки, Конвенция Африканского союза о защите лиц, перемещенных внутри страны, и оказании

23 The African Union IDPs Convention: a unique opportunity to strengthen the protection of the internally displaced in Africa. 14.10.2009. URL: http://www.fidh.org/The-AfricanUnion-IDPs-Convention-a-unique (accessed: 11.01.2011).

24 Согласно данному пункту государства - участники Конвенции должны обеспечить, чтобы вооруженные группы действовали в соответствии со своими обязательствами, предусмотренными статьей 7. 
им помощи в Африке является важным шагом вперед по пути закрепления юридически обязательных норм международного права о ЛПВС на международном уровне.

\section{International Cooperation of States in the Field of Internally Displaced Persons Protection (Summary)}

\section{Dmitri V. Ivanov*}

This article outlines history of international legal regulation of internally displaced persons (IDPs) protection; main theoretical aspects of the subject in question and examples of successful regional cooperation in the field of IDPs protection.

Keywords: international law; internally displaced persons (IDPs); internal displacement; forced resettler; forced migration.

\footnotetext{
* Dmitri V. Ivanov - Ph.D. in Law, professor of the Chair of International Law, MGIMOUniversity MFA Russia. ilc48@mail.ru.
} 